\title{
74 THE THREE I'S OF ADVANCE CARE PLANNING EDUCATION: INNOVATION, INTERDISCIPLINARY AND INTERACTIVE
}

10.1136/bmjspcare-2011-000053.74

\section{Hoffmann Fraser Health}

Fraser Healthy Authority (FHA) in British Columbia, Canada has been a champion and leader of Advance Care Planning (ACP) provincially and nationally.

Standardized education has been an integral part of the success of this program. Two 30 min on-line modules are augmented by $6 \mathrm{~h}$ classroom sessions. The on-line modules are interactive and focus on the importance of communication throughout the continuum of care. Classroom sessions provide an opportunity to discuss both personal and professional experiences, enhance ACP communication skills through practice exercises and further understanding of the legal underpinning as well as the role and responsibilities of professionals and substitute decision makers. Classroom sessions are purposely interdisciplinary and typically include professionals such as respiratory 
therapist, spiritual care practitioners, social workers, nurses, managers, care coordinators, etc who work in various program areas such as outpatient clinics, acute, residential and primary care. This assists to illustrate the number of professionals and perspectives patients and families encounter throughout their journey of care and the need for consistent and standardized ACP approach.

Though surveys and on-going feedback, students have stated FHAs education has provided a unique opportunity to learn from colleagues, enhance communication and decisional conflict skills. Students further note that following this education they were able to incorporate ACP with individuals not deemed at the 'end of life.' For example, students experienced an $11 \%$ increase in conversations with those individuals with chronic illnesses and a $21 \%$ increase with healthy adults. To date, 1500 healthcare professionals have completed education. 